\title{
Low temperature one-step synthesis of cobalt nanowires encapsulated in carbon
}

\author{
Justyna Majewska • Beata Michalkiewicz
}

Received: 11 February 2013 / Accepted: 7 April 2013 / Published online: 18 April 2013

(C) The Author(s) 2013. This article is published with open access at Springerlink.com

\begin{abstract}
The one-step method of carbon nanotubes filled with continuous cobalt nanowires (CoF-CNT) synthesis is presented. Co/ZSM-5 (8 wt\% Co) was used as catalyst for CoF-CNT production by methane decomposition at the temperature of $400{ }^{\circ} \mathrm{C}$ and $800{ }^{\circ} \mathrm{C}$ at atmospheric pressure in a conventional gas-flow system. The average diameter of the CoF-CNT is about 25 and $40 \mathrm{~nm}$ for products obtained at $400{ }^{\circ} \mathrm{C}$ and at $800{ }^{\circ} \mathrm{C}$, respectively. The average size of coherently scattering domains along the normal to graphite layers $L_{c}$, the interlayer spacing $d_{002}$, the graphitization degree of carbon, and the relative intensities of the $G$ and $D$ bands in Raman spectroscopy were determined to characterize the quality of carbon. It was proved that cobalt-filled carbon nanotubes can be produced by a simple method. The results of XRD, FE-SEM, and TEM show that CoF-CNT can be obtained even at $400{ }^{\circ} \mathrm{C}$ by catalytic decomposition of methane. On the basis of XRD, TEM, Raman spectroscopy was found that at a temperature of $800{ }^{\circ} \mathrm{C}$, a better quality of carbon was produced.
\end{abstract}

\section{Introduction}

The initial studies on carbon nanotubes (CNTs) filled with metals were carried out in 1993 by Iijima [1], which demonstrated the successful encapsulation of $\mathrm{Pb}$. In the following years, increasing effort was directed to the preparation of CNTs as template nanowires.

J. Majewska $\cdot$ B. Michalkiewicz ( $₫)$

The West Pomeranian University of Technology in Szczecin, ul. Pulaskiego 10, 70-322 Szczecin, Poland

e-mail: beata.michalkiewicz@ zut.edu.pl

Fax: +48-91-4494686
In order for metal filled CNT synthesis, several methods have been attempted. The CNT can be filled by a physical or chemical method [2]. In the physical method, the nanotubes are filled with melted metal due to the capillarity effect $[3,4]$. In the chemical method, the nanotubes are opened by boiling acid, then the inclusion of metal oxide or metal is carried out. One-step methods of metal filled CNT preparation are known as well. Mainly, an arc discharge technique was applied [3, 4], but it requires high temperatures.

Carbon nanotubes filled with continuous cobalt nanorods were synthesized by Liu et al. [5, 6] from $\mathrm{Co}(\mathrm{CO})_{3} \mathrm{NO}$. The reaction takes place in an autoclave at a temperature of $900{ }^{\circ} \mathrm{C}$ and at autogenic pressure.

Blank et al. [7] described cobalt-filled nanotube synthesis obtained from $\mathrm{CO}$ over $\mathrm{Co} / \mathrm{Y}$-zeolite catalysts. Despite the applied high temperature $\left(720^{\circ} \mathrm{C}\right)$ and pressure $(0.05 \mathrm{GPa})$ that was applied, TEM analysis showed the presence of some cobalt particles inside the carbon nanotubes. Long cobalt nanowires were not observed.

Some authors reported on methane to carbon nanotubes or nanoparticles decomposition over cobalt contained catalysts [8, 9], but to the best of our knowledge, there is no information on nanotubes filled with continuous cobalt nanowires prepared from methane.

The choice of cobalt as the material encapsulated inside carbon nanotubes (CNTs) is motivated by the interesting magnetic properties of composite cobalt-carbon nanomaterials, which are of great interest for various applications such as magnetic data storage, ferrofluids, or magnetic resonance imaging [10].

In this paper, we show that the Co/ZSM-5 prepared by the impregnation method can be used as catalysts of CNT filled with continuous cobalt nanowires (CoF-CNT) growth from methane decomposition even at the temperature of $400{ }^{\circ} \mathrm{C}$. 
This is the one-step method that is simpler and cheaper than the others described up to now.

\section{Experimental}

\subsection{Continuous cobalt nanowires synthesis}

Cobalt concentration in the catalyst was equal to $8 \mathrm{wt} \%$. The experimental setup and the catalyst preparation procedures had been reported in detail previously [11-13]. The CoFCNT growth was carried out at atmospheric pressure in a conventional gas-flow system. The catalyst $(1 \mathrm{~g})$ was placed into a veridical tube furnace. When the furnace reached $\left(700{ }^{\circ} \mathrm{C}\right)$ under nitrogen, hydrogen $\left(140 \mathrm{~cm}^{3} \mathrm{~min}^{-1}\right)$ was introduced to reduce the catalyst for $1 \mathrm{~h}$. Then the hydrogen flow was stopped, and the reactor was cooled down (under nitrogen) to $650{ }^{\circ} \mathrm{C}$. Methane was introduced into the reactor $\left(140 \mathrm{~cm}^{3} \mathrm{~min}^{-1}\right)$ and maintained for $15 \mathrm{~min}$. Then the furnace was switched off and methane was substituted by nitrogen.

\subsection{Characterization}

The morphology of as prepared cobalt nanorods was characterized by a Field Emission Scanning Electron Microscope (FE-SEM) equipped with a secondary electron (SE) and backscattered electron (BSE) detectors-Hitachi SU 8200 and Transmission Electron Microscope (TEM)-TEM-FEI Tecnai F20. The samples for FE-SEM were dispersed onto carbon tape without any metal coating. Specimens for the TEM measurements were prepared via drop casting a droplet of acetone suspension onto a copper grid, and dried at $200{ }^{\circ} \mathrm{C}$ for 5 minutes. Raman measurements were performed in a Renishaw InVia spectrometer using the $514.5 \mathrm{~nm}$ line of an $\mathrm{Ar}^{+}$laser. The X-ray diffraction patterns (XRD) of the products were recorded with a Philips X-pert Diffraction System using a $\mathrm{Cu} K_{\alpha}$ source $(\lambda=0.154178 \mathrm{~nm})$ in the range of $5 \leq 2 \theta \leq 100$ at room temperature. Before the XRD analysis, the catalyst was removed by a HF solution.

The average size of coherently scattering domains along the normal to graphite layers $L_{c}$, was determined from the full width at half-maximum of the reflection 002, after correcting for the instrumental broadening $\left(\beta_{002}\right)$ by the Scherrer equation [14]. The interlayer spacing $d_{002}$ was determined by using the Bragg law [12]. The graphitization degree of carbon was calculated by the Maire and Mering formula [15]. For ideal graphite with $d_{002}=0.3354 \mathrm{~nm}$, $g=1$; and for amorphous carbon with $d_{002}=0.344 \mathrm{~nm}$, $g=0$. In this definition, a $d_{002}$ spacing of $0.344 \mathrm{~nm}$ distinguishes a carbon with random orientation of layer planes (turbostratic) with no notable three-dimensional ordering [16].
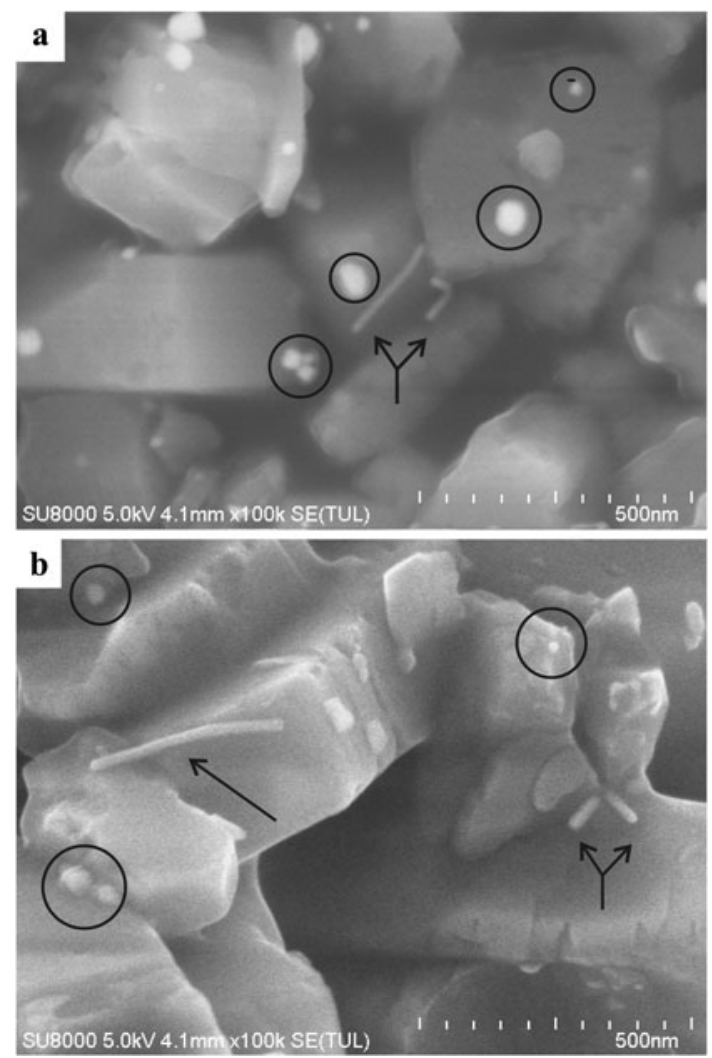

Fig. 1 FE-SEM images of CoF-CNT produced at $400{ }^{\circ} \mathrm{C}$ (a) and at $800{ }^{\circ} \mathrm{C}(\mathbf{b})$, magnitude 100 000, SE \& BSE detectors; arrows show cobalt nanowires, circles show metal particles

\section{Results and discussion}

The SEM images of the catalyst and CoF-CNT obtained at 400 and $800{ }^{\circ} \mathrm{C}$ are presented in Fig. 1. Since the BSE detector was applied, heavy elements backscatter electrons more strongly than light elements, and thus appear brighter in the image. Figure 1a shows a few cobalt particles (bright particles with a spherical morphology) and two cobalt nanowires (bright oblong shape). In Fig. 1b, the cobalt nanowire is observed.

TEM analysis of CoF-CNT obtained at 400 and $800{ }^{\circ} \mathrm{C}$ showed the presence of cobalt nanorods encapsulated inside the carbon tubes. The carbon produced at $400{ }^{\circ} \mathrm{C}$ seems to be amorphous whereas the graphitic lattice of a carbon nanotube can be clearly resolved, confirming the multiwalled nature of the carbon nanotube. The interplanar distance for the (002) planes of carbon layers measured from TEM micrographs (Fig. 2e) and was equal to $0.34 \mathrm{~nm}$. The average diameter of the CoF-CNT is about 25 and $40 \mathrm{~nm}$ for products obtained at $400{ }^{\circ} \mathrm{C}$ and at $800{ }^{\circ} \mathrm{C}$, respectively. On the basis of TEM micrographs at the lower magnification, one can conclude that at the temperature of $400{ }^{\circ} \mathrm{C}$ only cobalt nanorods encapsulated inside the carbon tubes are produced (Fig. 2c), whereas at $800{ }^{\circ} \mathrm{C}$ amorphous carbon and carbon nanotubes were produced as well (Fig. 2f). 
Fig. 2 TEM images of $\mathrm{CoF}-\mathrm{CNT}$ produced at $400{ }^{\circ} \mathrm{C}(\mathbf{a}),(\mathbf{b}),(\mathbf{c})$ and at $800^{\circ} \mathrm{C}(\mathbf{d}),(\mathbf{e}),(\mathbf{f})$
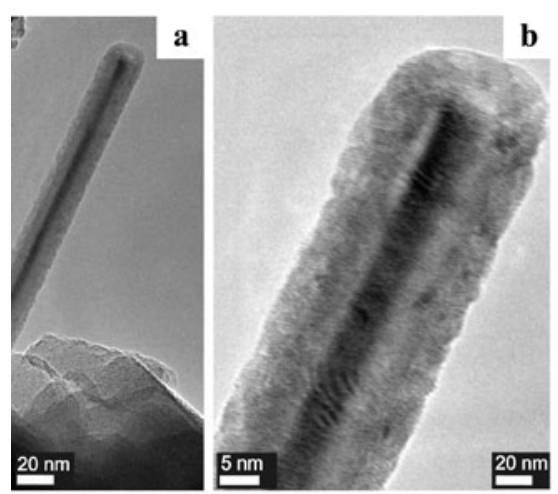

b

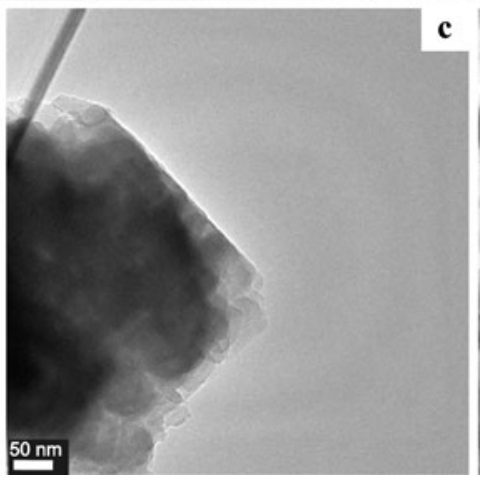

c

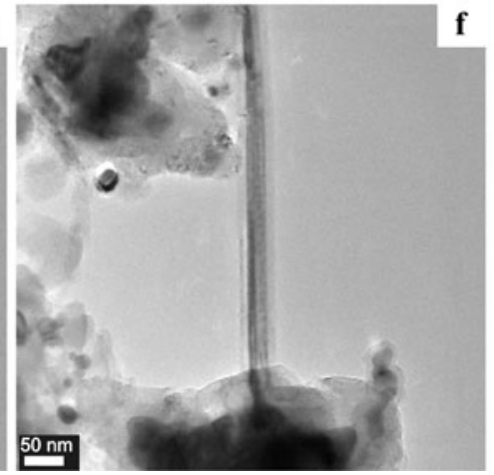

Fig. 3 The XRD pattern of CoF-CNT produced at $400{ }^{\circ} \mathrm{C}$ and at $800^{\circ} \mathrm{C}$

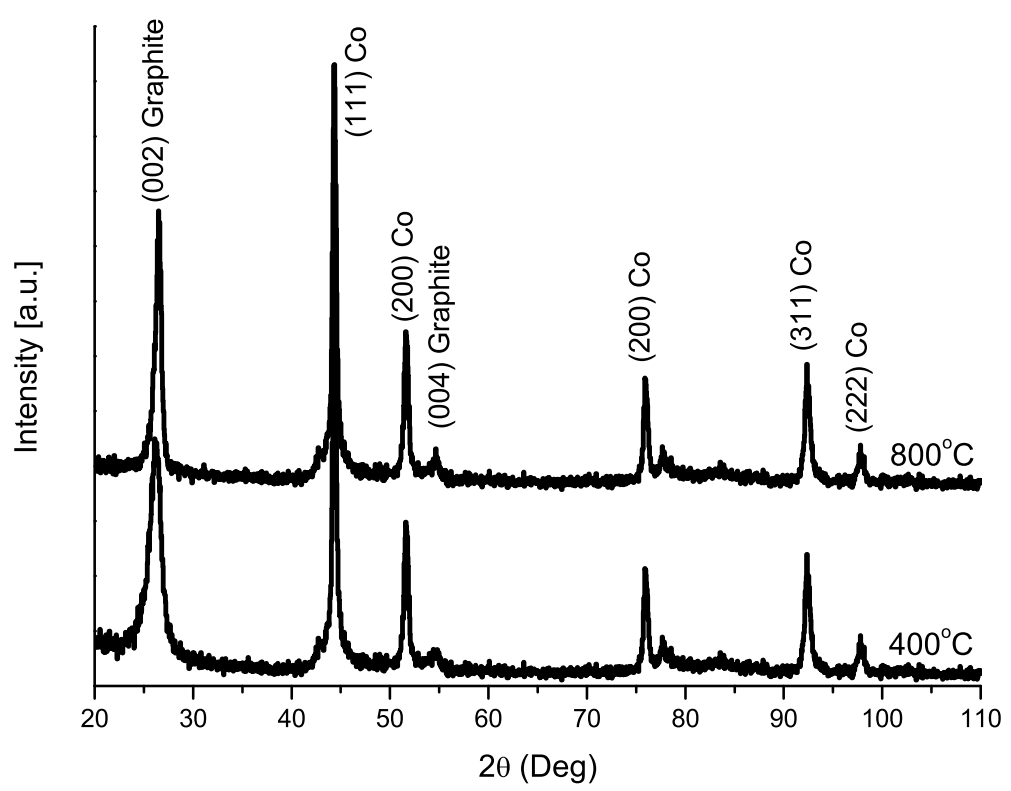

The XRD patterns of cobalt nanorods are shown in Fig. 3. For cobalt, all the five peaks $\left(2 \theta=44.26^{\circ}, 51.57^{\circ}\right.$, $75.93^{\circ}, 92.33^{\circ}, 97.77^{\circ}$ ) according to JCDPS, card no. 15 0806 are observed. The peaks can be indexed as (111), (200), (220), (311), and (222) and crystal planes indicate the formation of the face-centered cubic (fcc) structure.

Additionally, the two peaks at $2 \theta$ of 26.45 and 54.56 indexed as (002) and (004) indicate the presence of graphitelike carbon (JCPDS 08-0415).
The interplanar distance between the graphitic layers was determined on the basis of the accurate position of the prominent peak about $2 \theta=26^{\circ}$, which can be attributed to the (002) reflection of graphite. The interplanar distance was equal to $0.3518 \mathrm{~nm}$ and $0.3991 \mathrm{~nm}$ for carbon layers obtained at $800{ }^{\circ} \mathrm{C}$ and at $400{ }^{\circ} \mathrm{C}$, respectively. The graphitization degree of carbon obtained at $800{ }^{\circ} \mathrm{C}(0.91)$ was considerably higher than obtained at $400{ }^{\circ} \mathrm{C}(0.47)$. Statistically, the degree of graphitization is the probability of parallel orientation for two consecutive graphite layers. 
Fig. 4 Raman spectra of CoF-CNT produced at $400{ }^{\circ} \mathrm{C}$ (dashed line) and at $800{ }^{\circ} \mathrm{C}$ (solid line)

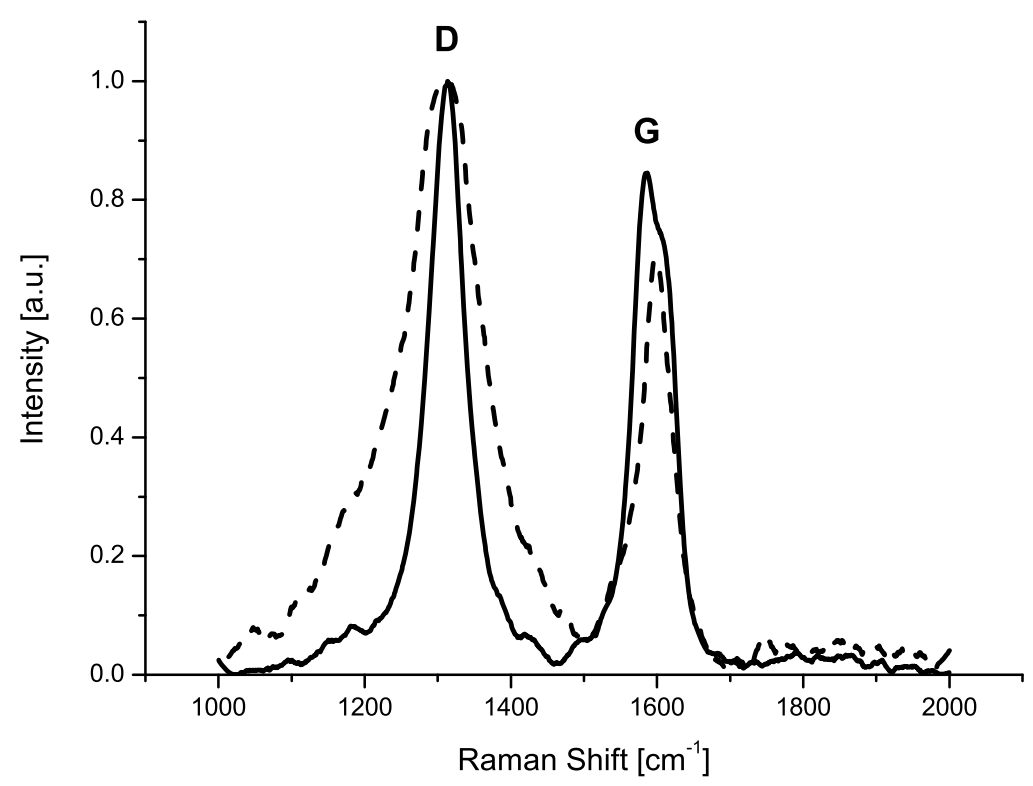

Raman spectra of CoF-CNT produced at $400{ }^{\circ} \mathrm{C}$ and at $800{ }^{\circ} \mathrm{C}$ are presented in Fig. 4 . Two bands were observed: at ca. $1310 \mathrm{~cm}^{-1}$ (D band) and at ca. $1600 \mathrm{~cm}^{-1}$ (G band). The $\mathrm{G}$ band can be attributed to the in-plane carbon-carbon stretching vibrations of graphite layers and the D band was thought to arise from structural imperfection of graphite. The relative intensities of the $\mathrm{G}$ and $\mathrm{D}$ bands, $I G / I D$ are a measure of the degree of perfection of carbon nanomaterials. $I G / I D$ was equal to 0.84 for CoF-CNT obtained at $800{ }^{\circ} \mathrm{C}$ and 0.69 for obtained at $400{ }^{\circ} \mathrm{C}$ ones.

\section{Conclusion}

In conclusion, cobalt-filled carbon nanotubes can be produced by the simple method. The results of XRD, FE-SEM, and TEM indicate that carbon nanotubes filled with cobalt nanowires can be prepared even at $400{ }^{\circ} \mathrm{C}$ by catalytic decomposition of methane. The results of XRD, TEM, and Raman spectroscopy show that at a temperature $800{ }^{\circ} \mathrm{C}$ a better quality of carbon was obtained.

Acknowledgement The project was financed by the National Science Centre of Poland (N N507 306240).

Open Access This article is distributed under the terms of the Creative Commons Attribution License which permits any use, distribution, and reproduction in any medium, provided the original author(s) and the source are credited.

\section{References}

1. P.M. Ajayan, S. Jijima, Nature 361, 603 (1993)

2. M. Xicheng, C. Yuanhua, L. Ning, A. Qing, L. Shenli, L. Fengzhao, W. Shulin, Mater. Lett. 57, 2879 (2003)

3. L. Zong-Jian, Ch. Renchao, X. Zhude, P. Lian-Mao, Synth. Met. 128, 191 (2002)

4. E. Dujardin, T.W. Ebbesen, H. Hiure, K. Tanigaki, Science $\mathbf{2 6 5}$, 1850 (1994)

5. S. Liu, J. Zhu, Y. Mastia, J. Felner, A. Gedanken, Chem. Mater. 12, 2205 (2000)

6. S. Liu, J. Zhu, Appl. Phys. A 70, 673 (2000)

7. V.D. Blank, B.A. Kulnitskiy, I.A. Perezhogin, E.V. Polyakov, D.V. Batov, Acta Mater. 58, 1293 (2010)

8. Ch. Siang-Piao, S.H.S. Zein, A.R. Mohamed, Chem. Phys. Lett. 426, 345 (2006)

9. N.A. Hermes, M.A. Lansarin, O.W. Perez-Lopez, Catal. Lett. 141, 1018 (2011)

10. O. Lehtinen, L. Sun, T. Nikitin, A.V. Krasheninnikov, L. Khriachtchev, J.A. Rodriguez-Manzo, M. Terrones, F. Banhart, J. Keinonen, Physica E 40, 2618 (2008)

11. J. Ziebro, I. Łukasiewicz, E. Borowiak-Palen, B. Michalkiewicz, Low temperature growth of carbon nanotubes from methane catalytic decomposition over nickel supported on a zeolite. Nanotechnology 21, 145308 (2010)

12. J. Ziebro, I. Łukasiewicz, B. Grzmil, E. Borowiak-Palen, B. Michalkiewicz, J. Alloys Compd. 485, 695 (2009)

13. J. Ziebro, B. Skorupińska, G. Kądziłoka, B. Michalkiewicz, Fuller. Nanotub. Carbon Nanostruct. 21, 333 (2013)

14. A. Manivannan, M. Chiril, N.C. Giles, M.S. Seehra, Carbon 37, 1741 (1999)

15. J. Maire, J. Mering, Chemistry and Physics of Carbon (Dekker, New York, 1970), p. 125

16. K. Kinoshita, K. Zaghi, J. Power Sources 110, 416 (2002) 